\title{
Rice, bread, noodle and cereal intake and colorectal cancer in Japanese men and women: the Japan Public Health Center-based prospective Study (JPHC Study)
}

\author{
S K Abe ${ }^{1}$, M Inoue ${ }^{\star 1,2}$, N Sawada ${ }^{2}, M$ Iwasaki $^{2}$, J Ishihara $^{2,3}$, S Sasazuki ${ }^{2}$, T Shimazu $^{2}$, T Yamaji $^{2}$, K Shibuya $^{1}$, \\ S Tsugane ${ }^{2}$ and the JPHC Study Group ${ }^{4}$ \\ ${ }^{1}$ Graduate School of Medicine, The University of Tokyo, 7-3-1 Hongo, Tokyo 113-0033, Japan; ${ }^{2}$ Epidemiology and Prevention \\ Division, Research Center for Cancer Prevention and Screening, National Cancer Center, 5-1-1 Tsukiji, Tokyo 104-0045, Japan and \\ ${ }^{3}$ Department of Nutrition Management, Sagami Women's University, 2-1-1 Bunkyo Minami Ward, Sagamihara 252-0307, Japan
}

Background: Colorectal cancer (CRC) incidence rate increased rapidly in Japan between the 1950s and 1990s. We examined the association between rice intake and CRC risk in comparison with bread, noodles and cereal among Japanese adults enrolled in the Japan Public Health Center-based prospective Study.

Methods: A total of 73501 Japanese men and women were followed-up from 1995 to 1999 until the end of 2008 for an average of 11 years. During 801937 person-years of follow-up, we identified 1276 incident cases of CRC. Hazard ratios (HRs) and $95 \%$ confidence intervals $(95 \% \mathrm{Cls}$ ) of CRC for rice, noodle, bread and cereal intake were calculated by Cox proportional hazards model.

Results: Overall, no significant association was observed for the highest quartile of rice intake compared with the lowest and the risk of $\mathrm{CRC}$ and its subsites in men $(\mathrm{HR}, 0.77 ; 95 \% \mathrm{Cl}, 0.56-1.07)$ and women $(\mathrm{HR}, 1.10 ; 95 \% \mathrm{Cl}, 0.71-1.68)$. However, a non-significant inverse trend was observed between rice intake and rectal cancer in men. No clear patterns of association were observed in bread, noodle and cereal intake.

Conclusion: Our findings suggest that the consumption of rice does not have a substantial impact on the risk of CRC in the Japanese population.

Colorectal cancer (CRC) is one of the most common cancers globally with considerable geographic variation (Bonithon-Kopp and Benhamiche, 1999; Ferlay et al, 2010). Environmental factors such as physical inactivity, body and abdominal fatness, red and processed meat and excess alcohol consumption may contribute to CRC incidence (Wynder et al, 1969; Haenszel et al, 1973; Takata et al, 2004; WCRF, 2007; Akhter et al, 2008). Some researchers speculate that the recent high CRC rates in Japan and Korea may be explained by a genetic predisposition, even when consuming a similar diet, caused by Asian's higher sensitivity and susceptibility to gastric and colon cancer (McMichael and Potter, 1985a; Le Marchand et al, 2002).

The increasing trend of CRC in Japan might also be attributed to the common lifestyle, including the consumption of cereals such as rice, which Japanese living overseas presumably continue to consume. Rice is a staple food in Japan, typically consumed in the

*Correspondence: Dr M Inoue; E-mail: mnminoue@m.u-tokyo.ac.jp
${ }^{4}$ Study group members are listed in Appendix.

Received 17 September 2013; revised 29 November 2013; accepted 1 December 2013; published online 2 January 2014 
form of white rice (Kenko Eiyo Joho Kenkyukai, 2009; Nanri et al, 2010; Science and Technology Agency, 2005; Uchida et al, 2010). There is also some, albeit limited, evidence from the $1970 \mathrm{~s}$ suggesting large quantities of rice may increase the risk of CRC (Burkitt, 1971; Haenszel et al, 1973). However, the evidence for rice and CRC risk in the general population has been sparse. Therefore, we for the first time analysed a large-scale prospective populationbased cohort to understand the association between CRC and rice intake in the Japanese population.

\section{MATERIALS AND METHODS}

Study population. The Japan Public Health Center-based prospective Study (JPHC Study) is a 30-year on-going cohort study focusing on cancer, cardiovascular and other lifestyle-related diseases, consisting of $\sim 140000$ Japanese citizens, aged 40-69 years at baseline (1990-1994), in 11 public health centres throughout Japan. The details of the study design have been described elsewhere (Tsugane and Sobue, 2001). Study participants responding to the 5-year follow-up questionnaire 1995-1999, aged 45-74 years were included in the present study. One public health centre area was excluded because cancer incidence information was not available. We started with a population-based cohort of 133323 participants. We excluded 245 disqualified subjects, 11583 subjects who had died, moved out of the study area or were lost to follow-up before the starting point. From these, 98505 responded to the questionnaire, (response rate $81.1 \%$ ). The study received approval from the institutional review board of the National Cancer Center, Tokyo, Japan (No. 13-021).
Dietary assessment. In the validated FFQ (Ishihara et al, 2003; Sasaki et al, 2003; Ishihara et al, 2006; Nanri et al, 2010), participants were asked about the frequency of consumption of individual food items as well as representative sizes relative to standard portions. Details regarding carbohydrate-related food items collected in the JPHC Study were described previously (Nanri et al, 2010). Briefly, for rice (japonica rice; round and short grain), participants selected from nine options ranging from $<1$ bowl per day to $\geqslant 10$ bowls per day and rice-bowl portion size: small ( $110 \mathrm{~g}$ of rice), medium (140 g of rice) and large (170 g of rice).

Follow-up and identification of CRC cases. Subjects were followed for move-out, death and occurrence of cancer from the 5-year follow-up survey (around 1995 and 1998) through 31 December 2008.

We identified CRC incidence by hospital records and population-based cancer registries in the study areas. We coded CRC cases as $\mathrm{C} 18-\mathrm{C} 20$ according to the International Classification of Diseases for Oncology, third edition. We further divided CRC into colon (C18.0-C18.5 for proximal colon and C18.6-C18.7 for distal colon) and rectal (C19 and C20) cancer.

Statistical analysis. We excluded participants who had been diagnosed with or reported as having cancer before the starting point $(n=4086)$ or subjects with missing information for main exposure variables: that is, rice, bread, noodle intake $(n=1030)$ or who reported extreme total energy intakes (upper $2.5 \%$ or lower $2.5 \% ; n=4666$ ) or missing data. A total of 88722 participants were enrolled in our analysis. Subjects with missing values for covariates were excluded $(n=15221)$, resulting in a final sample of 73501 men $(n=34559)$ and women $(n=38942)$.

Table 1. Age-adjusted characteristics of study participants at the 5-year follow-up survey according to quartiles of rice intake in the JPHC Study

\begin{tabular}{|c|c|c|c|c|c|c|c|c|c|c|}
\hline & \multicolumn{5}{|c|}{ Men $(n=34559)$} & \multicolumn{5}{|c|}{ Women $(n=38942)$} \\
\hline Variable & Q1 (low) & Q2 & Q3 & Q4 (high) & $\boldsymbol{P}$-value & Q1 (low) & Q2 & Q3 & Q4 (high) & $P$-value \\
\hline Rice $(n)$ & 8823 & 15444 & 5647 & 4645 & & 14837 & 5339 & 15430 & 3336 & \\
\hline $\begin{array}{l}\text { Rice (g per day) } \\
\text { median (range) }\end{array}$ & $122(0-136)$ & 183 (137-183) & $244(190-243)$ & 305 (273-592) & $<0.0001$ & $96(0-122)$ & $143(136-144)$ & $183(147-183)$ & $244(190-487)$ & $<0.0001$ \\
\hline Rice (g per day) & $92 \pm 0.45$ & $176 \pm 0.13$ & $238 \pm 0.14$ & $331 \pm 0.65$ & $<0.0001$ & $90 \pm 0.34$ & $140 \pm 0.05$ & $183 \pm 0.01$ & $263 \pm 0.80$ & $<0.0001$ \\
\hline Age (years) \pm s.d. & $56.78 \pm 7.90$ & $57.00 \pm 7.96$ & $55.16 \pm 7.06$ & $55.56 \pm 6.92$ & $<0.0001$ & $55.89 \pm 7.69$ & $57.39 \pm 7.83$ & $56.80 \pm 7.71$ & $55.74 \pm 7.10$ & $<0.0001$ \\
\hline BMI $\left(\mathrm{kg} \mathrm{m}^{-2}\right)$ & $23.72 \pm 0.03$ & $23.66 \pm 0.02$ & $23.45 \pm 0.04$ & $23.42 \pm 0.04$ & $<0.0001$ & $23.37 \pm 0.03$ & $23.67 \pm 0.04$ & $23.51 \pm 0.02$ & $23.40 \pm 0.06$ & $<0.0001$ \\
\hline Alcohol intake (\%) & 74.71 & 72.18 & 70.97 & 69.83 & $<0.0001$ & 22.67 & 15.88 & 15.74 & 15.74 & $<0.0001$ \\
\hline Current smoker (\%) & 45.71 & 45.89 & 51.98 & 50.48 & $<0.0001$ & 7.10 & 4.60 & 4.57 & 5.34 & $<0.0001$ \\
\hline METs (MET-h per day) & $31.57 \pm 0.07$ & $32.49 \pm 0.05$ & $33.68 \pm 0.10$ & $34.97 \pm 0.11$ & $<0.0001$ & $31.75 \pm 0.05$ & $32.22 \pm 0.08$ & $32.27 \pm 0.05$ & $32.83 \pm 0.10$ & $<0.0001$ \\
\hline $\begin{array}{l}\text { History of type } 2 \\
\text { diabetes (\%) }\end{array}$ & 10.00 & 10.06 & 6.97 & 5.64 & $<0.0001$ & 4.36 & 5.43 & 3.71 & 2.86 & $<0.0001$ \\
\hline CRC screening (\%) & 31.05 & 32.64 & 32.05 & 33.78 & NS & 29.93 & 33.20 & 34.54 & 30.37 & $<0.0001$ \\
\hline $\begin{array}{l}\text { Post-menopausal } \\
\text { status (\%) }\end{array}$ & - & - & - & - & - & 75.47 & 75.48 & 75.31 & 74.67 & NS \\
\hline Hormone use (\%) & - & - & - & - & - & 3.08 & 2.83 & 2.47 & 2.20 & $<0.0001$ \\
\hline \multicolumn{11}{|l|}{ Dietary intake } \\
\hline $\begin{array}{l}\text { Total energy } \\
\text { (kcal per day) }\end{array}$ & $1945.25 \pm 6.45$ & $2097.09 \pm 4.81$ & $2342.33 \pm 8.00$ & $2629.27 \pm 8.54$ & $<0.0001$ & $1732.93 \pm 4.38$ & $1882.57 \pm 7.47$ & $1948.50 \pm 4.30$ & $2210.65 \pm 9.37$ & $<0.0001$ \\
\hline Bread (g per day) & $32 \pm 0.49$ & $21 \pm 0.27$ & $20 \pm 0.45$ & $16 \pm 0.36$ & $<0.0001$ & $41 \pm 0.42$ & $23 \pm 0.41$ & $23 \pm 0.24$ & $23 \pm 0.63$ & $<0.0001$ \\
\hline Noodles (g per day) & $131 \pm 1.40$ & $117 \pm 0.91$ & $116 \pm 1.43$ & $110 \pm 1.51$ & $<0.0001$ & $96 \pm 0.81$ & $91 \pm 1.17$ & $91 \pm 0.69$ & $94 \pm 1.53$ & NS \\
\hline Cereals (g per day) & $285 \pm 1.59$ & $326 \pm 0.99$ & $385 \pm 1.59$ & $468 \pm 1.77$ & $<0.0001$ & $254 \pm 0.96$ & $284 \pm 1.36$ & $307 \pm 0.79$ & $392 \pm 1.94$ & $<0.0001$ \\
\hline Red meat (g per day) & $49 \pm 0.51$ & $49 \pm 0.35$ & $48 \pm 0.56$ & $46 \pm 0.60$ & NS & $42 \pm 0.33$ & $44 \pm 0.57$ & $43 \pm 32$ & $41 \pm 0.63$ & NS \\
\hline
\end{tabular}


We calculated person-years of follow-up for each participant from the starting point to the date of CRC diagnosis, date of emigration from the study area, date of death or end of the follow-up (31 December 2008), whichever came first. Using Cox proportional hazards models, we calculated the risk for developing CRC and its anatomic subsites for rice, bread, noodle and cereal categories in quartiles and per $100 \mathrm{~g}$ increase by sex, with the lowest consumption category as the reference, adjusted for potential confounding variables (indicated in Tables 2 and 3). The median value of each quartile was included in the trend analysis. Covariates were included based on associations found in our previous studies on CRC. Dietary factors were adjusted by total energy using the residual method (Kipnis et al, 1993; Brown et al, 1994; Willett et al, 1997; Akhter et al, 2008). All analyses were performed with Stata SE 12.1 (StataCorp, College Station, TX, USA).

\section{RESULTS}

During 801937 person-years of follow-up, we identified 1276 incident cases of CRC ( 777 for men and 499 for women) (Table 1). Age-adjusted CRC incidence ranged from 20.62 (highest quarter of rice) to 24.10 (lowest) in men and from 11.20 to 12.05 in women. Table 2 presents Hazard ratios (HRs) and 95\% confidence intervals (CIs) for CRC incidence according to quartile of rice, bread, noodle and cereal intake among Japanese men and women. The multivariate HRs for the highest compared with the lowest quartile of rice in men was 0.77 (95\% CI, $0.56-1.07)$. The trend analysis, analysed by scores, was not statistically significant. In women, no association was found for rice intake and CRC risk; however, a non-significant trend between increased cereal intake and the risk of CRC was found.

Table 2. Hazard ratio (HR) and $95 \% \mathrm{Cl}$ of colorectal cancer according to quartiles of rice, bread, noodle and cereal intake (g per day) in the JPHC Study

\begin{tabular}{|c|c|c|c|c|c|c|c|c|c|c|c|c|c|c|}
\hline & \multicolumn{7}{|c|}{ Men } & \multicolumn{7}{|c|}{ Women } \\
\hline & $\begin{array}{c}\text { Median } \\
\text { (g per } \\
\text { day) }\end{array}$ & $\begin{array}{c}\text { Range } \\
\text { (g per } \\
\text { day) }\end{array}$ & $\begin{array}{l}\text { No. } \\
\text { cases }\end{array}$ & $\begin{array}{l}\text { Person- } \\
\text { years }\end{array}$ & $\begin{array}{l}\text { Incidence } \\
\text { rate }^{a}\end{array}$ & HR & $(95 \% \mathrm{Cl})$ & $\begin{array}{c}\text { Median } \\
\text { (g per } \\
\text { day) }\end{array}$ & $\begin{array}{c}\text { Range } \\
\text { (g per } \\
\text { day) }\end{array}$ & $\begin{array}{l}\text { No. } \\
\text { cases }\end{array}$ & $\begin{array}{c}\text { Person- } \\
\text { years }\end{array}$ & $\begin{array}{l}\text { Incidence } \\
\text { rate }^{a}\end{array}$ & $\mathrm{HR}$ & $(95 \% \mathrm{Cl})$ \\
\hline \multicolumn{15}{|l|}{ Rice } \\
\hline Q1 & 122 & $0-136$ & 217 & 90336.74 & 24.10 & 1.00 & (Reference) & 96 & 0-122 & 174 & 161613.12 & 12.05 & 1.00 & (Reference) \\
\hline Q2 & 183 & $137-183$ & 338 & 161548.73 & 21.40 & 0.88 & $(0.73-1.06)$ & 143 & $136-144$ & 71 & 59833.11 & 12.51 & 1.10 & $(0.82-1.48)$ \\
\hline Q3 & 244 & 190-243 & 128 & 62110.34 & 22.89 & 0.91 & $(0.71-1.18)$ & 183 & $147-183$ & 216 & 174650.78 & 13.68 & 1.18 & $(0.92-1.50)$ \\
\hline Q4 & 305 & 273-592 & 94 & 52997.71 & 20.62 & 0.77 & $(0.56-1.07)$ & 244 & 190-487 & 38 & 38846.61 & 11.20 & 1.10 & $(0.71-1.68)$ \\
\hline$P$-trend & & & & & & \multicolumn{2}{|r|}{0.179} & & & & & & \multicolumn{2}{|r|}{0.312} \\
\hline Per $100 \mathrm{~g}$ & & & & & & 0.93 & $(0.82-1.04)$ & & & & & & 1.11 & $(0.92-1.35)$ \\
\hline \multicolumn{15}{|l|}{ Bread } \\
\hline Q1 & 4 & $0-4$ & 326 & 138252.72 & 24.76 & 1.00 & (Reference) & 4 & $0-4$ & 155 & 117202.34 & 13.89 & 1.00 & (Reference) \\
\hline Q2 & 13 & $6-13$ & 194 & 91057.57 & 23.18 & 1.05 & $(0.88-1.26)$ & 13 & $6-13$ & 137 & 112631.23 & 13.76 & 1.05 & $(0.83-1.33)$ \\
\hline Q3 & 19 & $15-30$ & 114 & 61917.40 & 20.30 & 0.97 & $(0.78-1.21)$ & 30 & $15-45$ & 108 & 100095.85 & 12.45 & 1.04 & $(0.80-1.35)$ \\
\hline Q4 & 60 & $45-720$ & 143 & 75765.81 & 19.69 & 0.98 & $(0.78-1.23)$ & 60 & $47-720$ & 99 & 105014.20 & 10.68 & 1.01 & $(0.75-1.36)$ \\
\hline$P$-trend & & & & & & \multicolumn{2}{|r|}{0.751} & & & & & & \multicolumn{2}{|r|}{0.986} \\
\hline Per $100 \mathrm{~g}$ & & & & & & 0.99 & $(0.78-1.26)$ & & & & & & 1.06 & $(0.77-1.45)$ \\
\hline \multicolumn{15}{|l|}{ Noodle } \\
\hline Q1 & 33 & $0-45$ & 210 & 106032.54 & 19.98 & 1.00 & (Reference) & 24 & $0-37$ & 129 & 98660.89 & 13.71 & 1.00 & (Reference) \\
\hline Q2 & 68 & $45-82$ & 170 & 73397.31 & 23.97 & 1.26 & $(1.02-1.54)$ & 45 & $38-68$ & 125 & 117114.14 & 12.09 & 0.90 & $(0.70-1.16)$ \\
\hline Q3 & 114 & 82-144 & 203 & 97244.08 & 22.99 & 1.18 & $(0.96-1.44)$ & 90 & 69-114 & 113 & 113433.45 & 11.54 & 0.88 & $(0.67-1.14)$ \\
\hline Q4 & 224 & $144-2800$ & 194 & 90319.58 & 23.85 & 1.18 & $(0.95-1.47)$ & 173 & 114-1875 & 132 & 105735.13 & 14.53 & 1.12 & $(0.85-1.47)$ \\
\hline$P$-trend & & & & & & \multicolumn{2}{|r|}{0.301} & & & & & & \multicolumn{2}{|r|}{0.230} \\
\hline Per $100 \mathrm{~g}$ & & & & & & 0.99 & $(0.77-1.26)$ & & & & & & 1.05 & $(0.77-1.45)$ \\
\hline \multicolumn{15}{|l|}{ Cereal } \\
\hline Q1 & 215 & $30-248$ & 193 & 86168.81 & 22.00 & 1.00 & (Reference) & 185 & $24-128$ & 116 & 99398.97 & 12.37 & 1.00 & (Reference) \\
\hline Q2 & 284 & $248-318$ & 200 & 90071.01 & 22.90 & 1.11 & $(0.90-1.36)$ & 241 & $218-267$ & 130 & 108611.76 & 13.18 & 1.15 & $(0.88-1.49)$ \\
\hline Q3 & 357 & $318-406$ & 196 & 94350.91 & 22.62 & 1.08 & $(0.87-1.36)$ & 297 & $267-334$ & 130 & 112772.49 & 13.08 & 1.19 & $(0.90-1.58)$ \\
\hline Q4 & 482 & $406-2983$ & 188 & 96402.78 & 22.36 & 1.07 & $(0.81-1.40)$ & 399 & $334-2110$ & 123 & 114160.40 & 12.59 & 1.21 & $(0.87-1.70)$ \\
\hline$P$-trend & & & & & & \multicolumn{2}{|r|}{0.780} & & & & & & \multicolumn{2}{|r|}{0.309} \\
\hline Per $100 \mathrm{~g}$ & & & & & & 0.96 & \begin{tabular}{|l}
$(0.84-1.09)$ \\
\end{tabular} & & & & & & 1.08 & $(0.88-1.32)$ \\
\hline $\begin{array}{l}\text { Abbreviatic } \\
\text { 150-299, } 30 \\
\text { day), BMI ( } \\
\text { (yes or no, } \\
\text { (according t } \\
\text { fatty acids ( } \\
\text { aAge-adjust }\end{array}$ & $\begin{array}{l}\text { day) and } \\
\text { cidence } r\end{array}$ & bre (g per da & Intake & of rice, bread a & noodles (g & er day, vit & $\begin{array}{l}\text { ( } h \text { per day), } \\
\text { nly), total ener } \\
\text { itamin } B 6 \text { (mg p } \\
\text { quartile) were } m\end{array}$ & tually adjus & B12 for; energy- & $\begin{array}{l}\text { ayy) folate } \\
\text { adjusted }\end{array}$ & $\begin{array}{l}\text { colorectal scr } \\
\text {, red meat in } \\
\text { (ug per day), vit } \\
\text { ereal intake w }\end{array}$ & $\begin{array}{l}\text { ening (yes or } \\
\text { ake ( } \mathrm{g} \text { per da } \\
\text { min } \mathrm{D}(\mu \mathrm{g} \text { per } \\
\mathrm{s} \text { analysed in a }\end{array}$ & $\begin{array}{l}\text { o), me } \\
\text { quarti } \\
\text { ay), } n-3 \\
\text { eparate }\end{array}$ & $\begin{array}{l}\text { drinker: }<150 \\
\text { cigarettes pe } \\
\text { hopausal statu } \\
\text { le) and intake } \\
\text { polyunsaturatec } \\
\text { model. }\end{array}$ \\
\hline
\end{tabular}


Further stratified analyses showed site-specific results: colon, rectum, proximal and distal colon cancer (Table 3). We noted a non-significant inverse association between the quartiles of rice intake and the risk of rectal cancer (Table 3 ) in men. In women, a non-significant trend of risk increase by quartile of rice intake and proximal colon cancer (Table 3) was found but not in men. Distal colon cancer showed no association with rice in both sexes (Table 3).

A non-significant risk trend was observed for bread, noodle and cereal intake (see Supplementary Tables).

Sensitivity analyses were performed excluding cases from the first 3 years of observation; because of the outcome, dietary habits might have been influenced by preclinical symptoms; however, results were not substantially different.

\section{DISCUSSION}

This is the first population-based study on the association between rice intake and CRC in Japan. Overall, we found that rice intake was not associated with CRC in men and women. Results were similar for CRC subsites.

The effect of rice on CRC is inconclusive, especially in Asian populations, consuming a diet high in white rice. The Shanghai Women's Health Study observed no association between rice intake and the risk of CRC (Li et al, 2011), which accords with the present result. In the case of Japan, descriptive data regarding the association between rice and CRC are inconsistent. Rice and CRC may be inversely associated as suggested by a decreasing trend of rice intake in Japan in recent decades (Kenko Eiyo Joho Kenkyukai, 2009) concurrent with increasing trends in CRC incidence. However, a positive link is implied by high mortality rates in prefectures where large amounts of rice are consumed (Tanaka et al, 2004; Ministry of Health Labour and Welfare, 2013a, b).
This inconsistency may confuse us to understand the association between rice intake and CRC.

Alternatively, rice intake may be a surrogate of a traditional Japanese diet and thus may represent specific dietary patterns associated with CRC risk. In particular, rice, not specifically white rice, may be an important source of dietary fibre, and a surrogate of starch. Fibre may have a protective role (Wakai et al, 2006, 2007; WCRF, 2007); however, results remain elusive. Refined carbohydrates are a possible aetiological factor related to CRC (Cleave, 1956) through two pathways: deficient fibre or bacterial changes degradation of bile salts to carcinogens and induction of tumours (Burkitt, 1971). Starch may be important in the production of short-chain fatty acids and stool quality (Uchida et al, 2010), possibly affecting the colon and rectum. Starch may enhance colorectal carcinogenesis via hyperinsulinaemia, assumed to be a mechanism in obesity-related carcinogenesis (Giovannucci and Michaud, 2007). Resistant starch may be protective (Uchida et al, 2010).

Some studies indicated that diet-associated risk was more prominent in proximal (right) colon cancer in women (McMichael and Potter, 1983, 1985a, 1985b), whereas rectal cancer was more common among men (Wynder et al, 1969; Bonithon-Kopp and Benhamiche, 1999). Our non-significant results hint at an inverse trend between rice intake and rectal cancer among men, mirror the findings of a Japanese case-control study in the southern part of the country suggesting that rice consumption is inversely associated with distal colon and rectal cancers (Uchida et al, 2010). The difference in risk by sex has also been indicated in previous studies where rice intake was found to be protective regarding risk of colon cancer in men (Wynder et al, 1969; Correa, 1981). In-depth sex- and CRC subsite-specific research is needed to draw more precise conclusions.

The JPHC Study has several strengths such as including a large general population sample with high response and low loss-to-

\begin{tabular}{|c|c|c|c|c|c|c|c|c|c|c|c|c|c|c|c|c|}
\hline & \multicolumn{8}{|c|}{ Men } & \multicolumn{8}{|c|}{ Women } \\
\hline & $\begin{array}{c}\text { Median } \\
\text { (g per } \\
\text { day) }\end{array}$ & $\begin{array}{l}\text { Range } \\
\text { (g per } \\
\text { day) }\end{array}$ & $\begin{array}{l}\text { No. } \\
\text { cases }\end{array}$ & $\mathrm{HR}$ & $(95 \% \mathrm{Cl})$ & $\begin{array}{l}\text { No. } \\
\text { cases }\end{array}$ & $\mathrm{HR}$ & $(95 \% \mathrm{Cl})$ & $\begin{array}{c}\text { Median } \\
\text { (g per } \\
\text { day) }\end{array}$ & $\begin{array}{l}\text { Range } \\
\text { (g per } \\
\text { day) }\end{array}$ & $\begin{array}{c}\text { No. } \\
\text { cases }\end{array}$ & $\mathrm{HR}$ & (95\% Cl) & $\begin{array}{c}\text { No. } \\
\text { cases }\end{array}$ & $\mathrm{HR}$ & $(95 \% \mathrm{Cl})$ \\
\hline \multicolumn{17}{|l|}{ Rice } \\
\hline & & & \multicolumn{3}{|c|}{ Colon } & \multicolumn{3}{|c|}{ Rectum } & & & \multicolumn{3}{|c|}{ Colon } & \multicolumn{3}{|c|}{ Rectum } \\
\hline Q1 & 122 & $0-136$ & 140 & 1.00 & (Reference) & 77 & 1.00 & (Reference) & 96 & $0-122$ & 121 & 1.00 & (Reference) & 53 & 1.00 & (Reference) \\
\hline Q2 & 183 & 137-183 & 226 & 0.93 & $(0.74-1.17)$ & 112 & 0.79 & $(0.58-1.08)$ & 143 & 136-144 & 45 & 1.02 & $(0.71-1.46)$ & 26 & 1.29 & $(0.78-2.13)$ \\
\hline Q3 & 244 & 190-243 & 87 & 1.01 & $(0.73-1.39)$ & 41 & 0.76 & $(0.49-1.18)$ & 183 & $147-183$ & 157 & 1.21 & $(0.90-1.61)$ & 59 & 1.12 & $(0.72-1.77)$ \\
\hline Q4 & 305 & 273-592 & 65 & 0.88 & $(0.58-1.32)$ & 29 & 0.61 & $(0.35-1.07)$ & 244 & 190-487 & 33 & 1.33 & $(0.82-2.16)$ & 5 & 0.51 & $(0.18-1.43)$ \\
\hline$P$-trend & & & & \multicolumn{2}{|r|}{0.685} & & \multicolumn{2}{|r|}{0.085} & & & & \multicolumn{2}{|r|}{0.156} & & \multicolumn{2}{|r|}{0.726} \\
\hline \multirow[t]{2}{*}{ per $100 \mathrm{~g}$} & & & & 0.98 & $(0.84-1.14)$ & & 0.84 & $(0.69-1.03)$ & & & & 1.16 & $(0.92-1.46)$ & & 1.01 & $(0.72-1.43)$ \\
\hline & & & \multicolumn{3}{|c|}{ Proximal colon } & \multicolumn{3}{|c|}{ Distal colon } & & & \multicolumn{3}{|c|}{ Proximal colon } & \multicolumn{3}{|c|}{ Distal colon } \\
\hline Q1 & 122 & $0-136$ & 57 & 1.00 & (Reference) & 76 & 1.00 & (Reference) & 96 & $0-122$ & 66 & 1.00 & (Reference) & 42 & 1.00 & (Reference) \\
\hline Q2 & 183 & 137-183 & 96 & 0.94 & $(0.66-1.34)$ & 114 & 0.92 & $(0.67-1.26)$ & 143 & 136-144 & 24 & 0.94 & $(0.57-1.53)$ & 21 & 1.52 & $(0.87-2.66)$ \\
\hline Q3 & 244 & 190-243 & 34 & 0.88 & $(0.53-1.45)$ & 49 & 1.15 & $(0.74-1.77)$ & 183 & 147-183 & 89 & 1.18 & $(0.80-1.73)$ & 61 & 1.52 & $(0.94-2.47)$ \\
\hline Q4 & 305 & $273-592$ & 36 & 1.00 & $(0.55-1.81)$ & 26 & 0.77 & $(0.42-1.39)$ & 244 & $190-487$ & 24 & 1.66 & $(0.90-3.05)$ & 5 & 0.68 & $(0.24-1.95)$ \\
\hline$P$-trend & & & & \multicolumn{2}{|r|}{0.903} & & \multicolumn{2}{|r|}{0.737} & & & & \multicolumn{2}{|r|}{0.139} & & \multicolumn{2}{|r|}{0.480} \\
\hline per $100 \mathrm{~g}$ & & & & 0.99 & $(0.79-1.24)$ & & 0.95 & $(0.77-1.17)$ & & & & 1.30 & $(0.96-1.76)$ & & 1.07 & \begin{tabular}{|l}
$(0.72-1.57)$ \\
\end{tabular} \\
\hline
\end{tabular}


follow-up rate, and exposure data selection before cancer diagnosis to exclude the recall bias. However, there are several limitations in the present study including some measurement error of long-term dietary intake by our FFQ (Ishihara et al, 2003), residual confounding effect that we failed to adjust and influence of improvements in CRC diagnostics on CRC incidence (Holford, 1991; Dubrow et al, 1993; Huang et al, 1999; Minami et al, 2006). In addition, we built quartiles of rice that were imbalanced in the number of subjects owing to several big peaks in the distribution.

Despite such limitations, the prospective JPHC Study suggests that the consumption of rice does not have a substantial impact on the risk of CRC in Japanese men and women. Further large prospective studies, especially in the Asian context are needed to confidently interpret these results.

\section{ACKNOWLEDGEMENTS}

We thank Dr Akiko Nanri and Dr Azusa Hara on advice regarding the nutrition variables. This work is supported by the National Cancer Center Research and Development Fund (23-A-31(toku)).

\section{CONFLICT OF INTEREST}

$\mathrm{MI}^{\star}$ is the beneficiary of a financial contribution from the AXA Research fund as chair holder of the AXA Department of Health and Human Security, Graduate School of Medicine, The University of Tokyo. The AXA Research Fund had no role in the design, data collection, analysis, interpretation or manuscript drafting or in the decision to submit the manuscript for publication. The remaining authors declare no conflict of interest.

\section{AUTHOR CONTRIBUTIONS}

SKA analysed the data, generated the tables and wrote the manuscript. $\mathrm{MI}^{\star}$ helped design the study and made comments regarding the intellectual content. JI and SS provided useful nutrition insights. TS, MI, TY and ST helped interpret the data in a meaningful way. NS and KS made substantial contributions strengthening the background and Discussion sections.

\section{REFERENCES}

Akhter M, Inoue M, Kurahashi N, Iwasaki M, Sasazuki S, Tsugane S (2008) Dietary soy and isoflavone intake and risk of colorectal cancer in the Japan public health center-based prospective study. Cancer Epidemiol Biomarkers Prev 17(8): 2128-2135.

Bonithon-Kopp C, Benhamiche AM (1999) Are there several colorectal cancers? Epidemiological data. Eur J Cancer Prev 8(Suppl 1): S3-S12.

Brown CC, Kipnis V, Freedman LS, Hartman AM, Schatzkin A, Wacholder S (1994) Energy adjustment methods for nutritional epidemiology: the effect of categorization. Am J Epidemiol 139(3): 323-338.

Burkitt DP (1971) Some neglected leads to cancer causation. J Natl Cancer Inst 47(5): 913-919.

Cleave TL (1956) The neglect of natural principles in current medical practice. J R Nav Med Serv 42(2): 54-83.

Correa P (1981) Epidemiological correlations between diet and cancer frequency. Cancer Res 41(9 Pt 2): 3685-3690.

Dubrow R, Bernstein J, Holford TR (1993) Age-period-cohort modelling of large-bowel-cancer incidence by anatomic sub-site and sex in Connecticut. Intl J Cancer 53(6): 907-913.

Ferlay J, Shin HR, Bray F, Forman D, Mathers C, Parkin DM (2010) GLOBOCAN 2008 v2.0, Cancer Incidence and Mortality Worldwide. IARC CancerBase No. 10 [Internet]. Lyon, France: International Agency for Research on Cancer. Available from http://globocan.iarc.fr (accessed 12/12/2012).
Giovannucci E, Michaud D (2007) The role of obesity and related metabolic disturbances in cancers of the colon, prostate, and pancreas. Gastroenterology 132(6): 2208-2225.

Haenszel W, Berg JW, Segi M, Kurihara M, Locke FB (1973) Large-bowel cancer in Hawaiian Japanese. J Natl Cancer Inst 51(6): 1765-1779.

Holford TR (1991) Understanding the effects of age, period, and cohort on incidence and mortality rates. Annu Rev Public Healt 12: 425-457.

Huang J, Seow A, Shi CY, Lee HP (1999) Colorectal carcinoma among ethnic Chinese in Singapore: trends in incidence rate by anatomic subsite from 1968 to 1992 . Cancer 85(12): 2519-2525.

Ishihara J, Inoue M, Kobayashi M, Tanaka S, Yamamoto S, Iso H, Tsugane S (2006) Impact of the revision of a nutrient database on the validity of a self-administered food frequency questionnaire (FFQ). J Epidemiol 16(3): 107-116.

Ishihara J, Sobue T, Yamamoto S, Yoshimi I, Sasaki S, Kobayashi M, Takahashi T, Iitoi Y, Akabane M, Tsugane S (2003) Validity and reproducibility of a self-administered food frequency questionnaire in the JPHC Study Cohort II: study design, participant profile and results in comparison with Cohort I. J Epidemiol 13(1 Suppl): S134-S147.

Kenko Eiyo Joho Kenkyukai (2009) (in Japanese) The National Health and Nutrition Survey in Japan, 2006. Daiichi-Shuppan: Tokyo, Japan.

Kipnis V, Freedman LS, Brown CC, Hartman A, Schatzkin A, Wacholder S (1993) Interpretation of energy adjustment models for nutritional epidemiology. Am J Epidemiol 137(12): 1376-1380.

Le Marchand L, Hankin JH, Pierce LM, Sinha R, Nerurkar PV, Franke AA, Wilkens LR, Kolonel LN, Donlon T, Seifried A, Custer LJ, Lum-Jones A, Chang W (2002) Well-done red meat, metabolic phenotypes and colorectal cancer in Hawaii. Mutat Res 506-507: 205-214.

Li HL, Yang G, Shu XO, Xiang YB, Chow WH, Ji BT, Zhang X, Cai H, Gao J, Gao YT, Zheng W (2011) Dietary glycemic load and risk of colorectal cancer in Chinese women. Am J Clin Nutr 93(1): 101-107.

McMichael AJ, Potter JD (1983) Do intrinsic sex differences in lower alimentary tract physiology influence the sex-specific risks of bowel cancer and other biliary and intestinal diseases? Am J Epidemio 118(5): 620-627.

McMichael AJ, Potter JD (1985a) Diet and colon cancer: integration of the descriptive, analytic, and metabolic epidemiology. Natl Cancer Inst Monogr 69: 223-228.

McMichael AJ, Potter JD (1985b) Host factors in carcinogenesis: certain bile-acid metabolic profiles that selectively increase the risk of proximal colon cancer. J Natl Cancer Inst 75(2): 185-191.

Minami Y, Nishino Y, Tsubono Y, Tsuji I, Hisamichi S (2006) Increase of colon and rectal cancer incidence rates in Japan: trends in incidence rates in Miyagi Prefecture, 1959-1997. J Epidemiol 16(6): 240-248.

Ministry of Health Labour and Welfare (2013a) (in Japanese) National Health and Nutrition Survey, 2011. Ministry of Health Labour and Welfare: Tokyo, Japan.

Ministry of Health Labour and Welfare (2013b) (in Japanese) Vital Statistics of Japan. Ministry of Health Labour and Welfare: Tokyo, Japan.

Nanri A, Mizoue T, Noda M, Takahashi Y, Kato M, Inoue M, Tsugane S (2010) Rice intake and type 2 diabetes in Japanese men and women: the Japan Public Health Center-based Prospective Study. Am J Clin Nutr 92(6): 1468-1477.

Sasaki S, Takahashi T, Iitoi Y, Iwase Y, Kobayashi M, Ishihara J, Akabane M, Tsugane S (2003) Food and nutrient intakes assessed with dietary records for the validation study of a self-administered food frequency questionnaire in JPHC Study Cohort I. J Epidemiol 13(1 Suppl): S23-S50.

Science and Technology Agency (2005) (in Japanese) Standard Tables of Food Composition in Japan. Printing Bureau of the Ministry of Finance: Tokyo, Japan.

Takata Y, Maskarinec G, Franke A, Nagata C, Shimizu H (2004) A comparison of dietary habits among women in Japan and Hawaii. Public Health Nutr 7(2): 319-326.

Tanaka H, Nakamura M, Yoiike N (2004) Analysing Nutrition-Related Indicators by Province Using National Health and Nutrition Survey data, 2002. Vol. 2013. Tokyo, Japan.

Tsugane S, Sobue T (2001) Baseline survey of JPHC study-design and participation rate. Japan Public Health Center-based Prospective Study on Cancer and Cardiovascular Diseases. J Epidemiol 11(6 Suppl): S24-S29.

Uchida K, Kono S, Yin G, Toyomura K, Nagano J, Mizoue T, Mibu R, Tanaka M, Kakeji Y, Maehara Y, Okamura T, Ikejiri K, Futami K, Maekawa T, Yasunami Y, Takenaka K, Ichimiya H, Terasaka R (2010) Dietary fiber, source foods and colorectal cancer risk: the Fukuoka Colorectal Cancer Study. Scand J Gastroenterol 45(10): 1223-1231. 
Wakai K, Date C, Fukui M, Tamakoshi K, Watanabe Y, Hayakawa N, Kojima M, Kawado M, Suzuki K, Hashimoto S, Tokudome S, Ozasa K, Suzuki S, Toyoshima H, Ito Y, Tamakoshi A (2007) Dietary fiber and risk of colorectal cancer in the Japan collaborative cohort study. Cancer Epidemiol Biomarkers Prev 16(4): 668-675.

Wakai K, Hirose K, Matsuo K, Ito H, Kuriki K, Suzuki T, Kato T, Hirai T, Kanemitsu Y, Tajima K (2006) Dietary risk factors for colon and rectal cancers: a comparative case-control study. J Epidemiol 16(3): 125-135.
WCRF (2007) Food, Nutrition, Physical Activity, and the Prevention of Cancer: a Global Perspective. AICR: Washington, DC.

Willett WC, Howe GR, Kushi LH (1997) Adjustment for total energy intake in epidemiologic studies. Am J Clin Nutr 65(4 Suppl): 1220S-1228S.

Wynder EL, Kajitani T, Ishikawa S, Dodo H, Takano A (1969) Environmental factors of cancer of the colon and rectum. II. Japanese epidemiological data. Cancer 23(5): 1210-1220.

Supplementary Information accompanies this paper on British Journal of Cancer website (http://www.nature.com/bjc)

APPENDIX

Members of the Japan Public Health Center-based Prospective Study (JPHC Study, principal investigator: S Tsugane) Group are: S Tsugane, S Sasazuki, M Iwasaki, N Sawada, T Shimazu, T Yamaji and T Hanaoka, National Cancer Center, Tokyo; J Ogata, S Baba, T Mannami, A Okayama and Y Kokubo, National Cerebral and Cardiovascular Center, Osaka; K Miyakawa, F Saito, A Koizumi, Y Sano, I Hashimoto, T Ikuta and Y Tanaba, H Sato, Iwate Prefectural Ninohe Public Health Center, Iwate; Y Miyajima, N Suzuki, S Nagasawa, Y Furusugi, N Nagai, Y Ito and Y Roppongi, Akita Prefectural Yokote Public Health Center, Akita; H Sanada, Y Hatayama, F Kobayashi, H Uchino, Y Shirai, T Kondo, R Sasaki, Y Watanabe, Y Miyagawa, Y Kobayashi, M Machida and K Kobayashi, Nagano Prefectural Saku Public Health Center, Nagano; Y Kishimoto, E Takara, T Fukuyama, M Kinjo, M Irei and $\mathrm{H}$ Sakiyama, Okinawa Prefectural Chubu Public Health Center, Okinawa; K Imoto, $\mathrm{H}$ Yazawa, $\mathrm{T}$ Seo, A Seiko, F Ito, F Shoji and R Saito, Katsushika Public Health Center, Tokyo; A Murata, K Minato, K Motegi, T Fujieda and S Yamato, Ibaraki Prefectural Mito Public Health Center, Ibaraki; K Matsui, T Abe, M Katagiri, M Suzuki, K and Matsui, Niigata Prefectural Kashiwazaki and Nagaoka Public Health Center, Niigata; $M$ Doi, A Terao, $Y$ Ishikawa and $\mathrm{T}$ Tagami, Kochi Prefectural Chuo-higashi Public Health Center, Kochi; H Sueta, H Doi, M Urata, N Okamoto, and F Ide and H Goto,
Nagasaki Prefectural Kamigoto Public Health Center, Nagasaki; H Sakiyama, N Onga, H Takaesu, M Uehara and T Nakasone, Okinawa Prefectural Miyako Public Health Center, Okinawa; F Horii, I Asano, H Yamaguchi, K Aoki, S Maruyama, M Ichii and M Takano, Osaka Prefectural Suita Public Health Center, Osaka; Y Tsubono, Tohoku University, Miyagi; K Suzuki, Research Institute for Brain and Blood Vessels Akita, Akita; Y Honda, K Yamagishi, S Sakurai and N Tsuchiya, University, Ibaraki; M Kabuto, National Institute for Environmental Studies, Ibaraki; M Yamaguchi, Y Matsumura, S Sasaki and S Watanabe, National Institute of Health and Nutrition, Tokyo; M Akabane, Tokyo University of Agriculture, Tokyo; T Kadowaki and M Inoue, The University of Tokyo, Tokyo; M Noda and T Mizoue, National Center for Global Health and Medicine, Tokyo; Y Kawaguchi, Tokyo Medical and Dental University, Tokyo; Y Takashima and Y Yoshida, Kyorin University, Tokyo; K Nakamura, Niigata University, Niigata; S Matsushima and S Natsukawa, Saku General Hospital, Nagano; H Shimizu, Sakihae Institute, Gifu; H Sugimura, Hamamatsu University School of Medicine, Shizuoka; S Tominaga, Aichi Cancer Center, Aichi; N Hamajima, Nagoya University, Aichi; H Iso and T Sobue, Osaka University, Osaka; M Iida, W Ajiki and A Ioka, Osaka Medical Center for Cancer and Cardiovascular Disease, Osaka; S Sato, Chiba Prefectural Institute of Public Health, Chiba; E Maruyama, Kobe University, Hyogo; M Konishi, K Okada and I Saito, Ehime University, Ehime; N Yasuda, Kochi University, Kochi; S Kono, Kyushu University, Fukuoka; S Akiba, Kagoshima University, Kagoshima. 